\title{
Pelatihan Membuat dan Mempercantik Blog Untuk Remaja Pada Karang Taruna Katana 22 Bekasi
}

\author{
Nicodias Palasara ${ }^{1}$, Anna Mukhayaroh ${ }^{1, *}$, Adelia Alvi Yana ${ }^{1}$, Juarni Siregar ${ }^{1}$, \\ Ani Yoraeni ${ }^{1}$ \\ ${ }^{1}$ Fakultas Teknologi Informasi; Universitas Nusa Mandiri, Jl. Jatiwaringin Raya No. 2 Kelurahan \\ Cipinang Melayu, Kecamatan Makasar, Jakarta Timur, telp. (021) 8005722; e-mail: \\ nico.ncp@nusamandiri.ac.id, anna.auh@nusamandiri.ac.id, adelia.aav@nusamandiri.ac.id, \\ juarni.jsr@nusamandiri.ac.id, ani.ayr@nusamandiri.ac.id \\ *Korespondensi: e-mail: anna.auh@nusamandiri.ac.id
}

Submitted: 03/06/2021; Revised: 10/06/2021; Accepted: 16/06/2021; Published: 28/06/2021

\begin{abstract}
Youth is the next generation of the nation. Youth is a potential investment that needs good guidance and assistance, so that its activities can be directed and participate in the development of the nation and state. For this reason, it is necessary to accommodate their activeness and creativity in directed organizational associations. In Pengasinan Village, Rawa Lumbu Sub-district, Bekasi City, a Katana 22 Youth Organization has been formed, precisely in RW.022 Pengasinan Village, Rawa Lumbu Sub-district, Taman Narogong Indah Housing Estate, Bekasi City, which is stipulated by a Decree of the Village Head of Pengasinan. At the youth organization a lot of expertise is given in the field of management, human resources related to youth development programs. The problem that exists at Karang Taruna Katana 22 is that they do not understand the use of blogs in organizational activities. For this reason, Nusa Mandiri University lecturers and students hold community service activities in the form of learning to create blogs so that youth youth organizations can use it as a promotional event, adding to the creativity of youth youth writing activities.
\end{abstract}

Keywords: Blog, Training, Youth Organization

\begin{abstract}
Abstrak
Pemuda merupakan generasi penerus bangsa. Pemuda merupakan investasi potensi yang perlu mendapat bimbingan dan pendampingan secara baik, sehingga kegiatannya bisa terarah dan berperan serta dalam pembangunan bangsa dan negara. Untuk itu perlu diwadahi keaktifan dan kreativitasnya dalam perkumpulan organisasi yang terarah. Di Kelurahan Pengasinan Kecamatan Rawa Lumbu Kota Bekasi telah terbentuk Karang Taruna Katana 22 tepatnya di RW.022 Kelurahan Pengasinan Kecamatan Rawa Lumbu Perumahan Taman Narogong Indah Kota Bekasi yang ditetapkan dengan Surat Keputusan Lurah Pengasinan. Pada karang taruna banyak keahlian yang diberikan di bidang manajemen, sumber daya manusia yang terkait dengan program perkembangan karang taruna. Permasalahan yang ada pada Karang Taruna Katana 22 yaitu kurang paham penggunaan blog dalam kegiatan berorganiasasi. Untuk itu dosen dan mahasiswa Universitas Nusa Mandiri mengadakan kegiatan pengabdian kepada masyarakat berupa pembelajaran pembuatan blog agar para remaja karang taruna dapat memanfaatkannya sebagai ajang promosi, menambah kreatifitas kegiatan menulis para remaja karang taruna.
\end{abstract}

Kata kunci: Blog, Pelatihan, Karang Taruna 


\section{Pendahuluan}

Menurut Peraturan Menteri Kesehatan RI Nomor 25 tahun 2014, arti remaja merupakan penduduk yang berusia 10-19 tahun (Kemenkes RI, 2014). Remaja adalah generasi penerus, dimana sosok remaja diharapkan dapat melanjutkan perjuangan generasi sebelumnya. Suatu bangsa pastinya memiliki harapan yang besar agar pada masa yang akan datang remaja dapat menjadikan bangsa Indonesia ini bangsa yang lebih maju. Oleh karenanya remaja adalah aset negara yang tak ternilai harganya.

Karang taruna merupakan salah satu organisasi pemuda yang tidak asing lagi karena merupakan wadah yang telah memiliki misi untuk membina generasi muda khususnya di pedesaan. Adapun visi karang taruna yaitu sebagai wadah pembinaan dan pengembangan kreativitas generasi muda yang berkelanjutan untuk menjalin persaudaraan dan rasa kebersamaan menjadi mitra organisasi lembaga, baik kepemudaan ataupun pemerintah dalam pengembangan kreativitas (Adi, M. R. Arief, 2014). Sebagai organisasi sosial kepemudaan Karang Taruna merupakan wadah pembinaan dan pengembangan serta pemberdayaan dalam upaya mengembangkan kegiatan ekonomis produktif dengan pendayagunaan semua potensi yang tersedia dilingkungan baik sumber daya manusia maupun sumber daya alam yang telah ada. Karang Taruna Katana 22 beranggotakan pemuda dan pemudi (dalam AD/ART nya diatur keanggotaannya mulai dari pemuda/i berusia mulai dari 11 - 45 tahun) dan batasan sebagai Pengurus adalah berusia mulai $17-35$ tahun.

Pengabdian masyarakat adalah suatu kegiatan yang bertujuan membantu masyarakat tertentu dalam beberapa aktivitas tanpa mengharapkan imbalan dalam bentuk apapun. Secara umum program ini dirancang oleh berbagai universitas atau institut yang ada di Indonesia untuk memberikan kontribusi nyata bagi bangsa Indonesia, khususnya dalam mengembangkan kesejahteraan dan kemajuan bangsa Indonesia. Kegiatan Pengabdian Masyarakat merupakan salah satu bagian dari Tri Dharma Perguruan Tinggi. Dan sudah menjadi kewajiban bagi kalangan akademik untuk memenuhinya.

Civitas akademi Universitas Nusa Mandiri, yaitu dosen dan mahasiswa melihat masalah yang terjadi pada Karang Taruna Katana 22 yaitu pada masa pandemi yang mengharuskan dirumah, sehingga tidak adanya kegiatan, maka dari itu para remaja menginginkan pengetahuan mengenai blog, karena banyak yang kurang paham cara membuatnya. Para remaja saat ini kurang semangat dalam menulis dan tidak ada wadah untuk menaruh tulisan disaat pandemi karena mading kantor RW ditutup, pada masa pandemi.

Blog memenuhi kriteria suatu media yang digunakan dalam pendidikan. Hal ini karena blog sangat fleksibel dalam penggunaannya karena dapat diakses kapanpun dan dimanapun (Fatmawati, 2015). Beberapa penelitian telah dilakukan dalam mengembangkan media pembelajaran blog dalam pembelajaran untuk mempermudah proses pembelajaran, sebagai upaya meningkatkan hasil belajar, sebagai sarana informasi, menanamkan karakter kritis dan kreatif dan sebagai penunjang dalam belajar (Fajriah et al., 2017) (Ratnasari \& Hamdan, 2015) 
(Rhamandica et al., 2016) (Sunismi \& Fathani, 2017) (Weni \& Isnani, 2016) (Khairul Basyar, 2017)

Oleh karenanya diperlukan pelatihan-pelatihan bagi kalangan remaja Karang Taruna Katana 22 untuk membangkitkan semangat dalam menulis, memberikan motivasi menulis sebagai upaya berbagi ilmu dan pengalaman.

\section{Metode Pelaksanaan}

Dalam menunjang pelaksanaan kegiatan pengabdian masyarakat ini. Metode Pengabdian Masyarakat yang digunakan dikutip berdasarkan (Pressmann, 2015) menggunakan metode SDLC yaitu Requirment, Design, Implementation, Verification, Maintenance.

1) Requirement dilakukan pada saat pengumpulan data dan persyaratan yang digunakan untuk pemenuhan kebutuhan; 2) Desain adalah cara dan teknik yang digunakan dalam membangun blog tersebut dengan mudah dan sederhana sehingga dapat menarik minat pengunjung untuk melihat blog tersebut; 3) Implementation adalah penerapan blog sebagai salah satu media menaruh tulisan dan kegiatan karang taruna remaja katana 22 agar dapat dilihat oleh masyarakat; 4) Verification, merupakan salah satu cara untuk merekam, menyimpan secara terstruktur user yang mengunjungi blog tersebut dan terdapat security key agar lebih aman dan valid. Serta terjaminnya data-data user yang berkunjung; 4) Maintenance digunakan untuk menjaga traffic pengunjung agar tetap stabil dan meningkat.

Adapun metode pelatihan dalam mengatasi permasalahan yang telah dijelaskan pada bab sebelumnya yaitu dengan cara pelatihan berupa teknik dan cara pembuatan blog dengan menyampaikan ceramah, tanya jawab serta diskusi. Sedangkan praktikum yang dilakukan berupa teknik simulasi dan uji coba blog tersebut.

\section{Hasil dan Pembahasan}

Pengabdian Masyarakat merupakan salah satu pilar Tri Dharma Perguruan Tinggi, disamping dharma pendidikan dan pengajaran serta dharma penelitian. Pengabdian kepada masyarakat merupakan pelaksanaan pengamalan ilmu pengetahuan, teknologi dan seni budaya langsung pada masyarakat secara kelembagaan melalui metodologi ilmiah sebagai penyebaran Tri Dharma Perguruan Tinggi serta tanggung jawab yang luhur dalam usaha mengembangkan kemampuan masyarakat, sehingga dapat mempercepat laju pertumbuhan tercapainya tujuan pembangunan nasional. Universitas Nusa Mandiri melalui kegiatan pengabdian masyarakat berupaya untuk hadir ditengah-tengah masyarakat Indonesia membantu menganalisis permasalahan dan mengembangkan potensi masyarakat Indonesia.

\subsection{Lokasi Pengabdian Kepada Masyarakat}

Lokasi kegiatan tersebut dilaksanakan di kantor Sekretariat RW 022, Perumahan Taman Narogong Indah, Kelurahan Pengasinan, Kecamatan Rawalumbu Kota Bekasi. Permasalahan yang terjadi pada karang taruna katana 22 adalah kurang semangat menulis dan berkarya karena tidak adanya wadah untuk menampilkan kegiatan-kegiatan salah satunya berupa tulisan 
pada masa pandemi, karena yang biasanya sebelum pandemi mereka menampilkannya di mading kantor RW 022, sekarang tidak ada yang lihat. Untuk mencapai tujuan menulis kreatif itu sendiri, tentunya orientasi pembelajaran adalah mahasiswa yang memiliki kesadaran dan hobi untuk selalu membaca dan menulis sehingga para remaja dapat menulis dengan baik dan tulisan- tulisannya dapat dibaca dan dipublikasikan (Fitria, 2013) .Solusi yang diberikan adalah membuat blog khusus untuk Karang Taruna Katana 22, dan permasalahan kedua para remaja kurang paham dalam membuat blog, maka karena itu dosen-dosen dari Universitas Nusa Mandiri mengajarkan bagaimana proses pembuatan blog dan mempercantiknya.

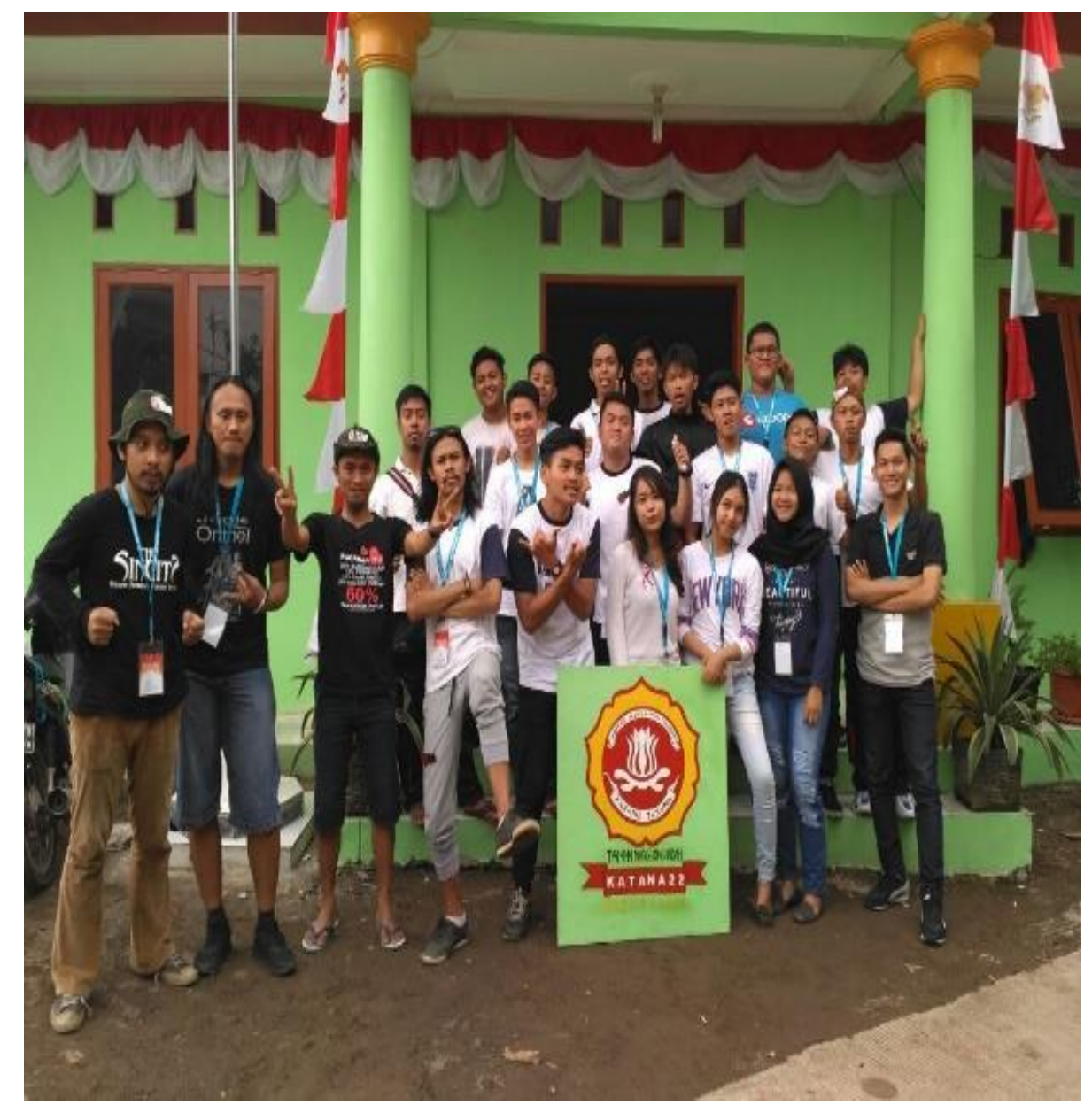

Sumber: Hasil Pelaksanaan (2021)

Gambar 1. Remaja anggota Karang Taruna Katana 22.

Terlihat pada gambar 1 para remaja anggota Karang Taruna Katana 22, gambar 1 ini diambil sebelum pandemi Covid-19. Pada gambar 2 menunjukkan peta lokasi pihak mitra dari kegiatan pengabdian kepada masyarakat. 


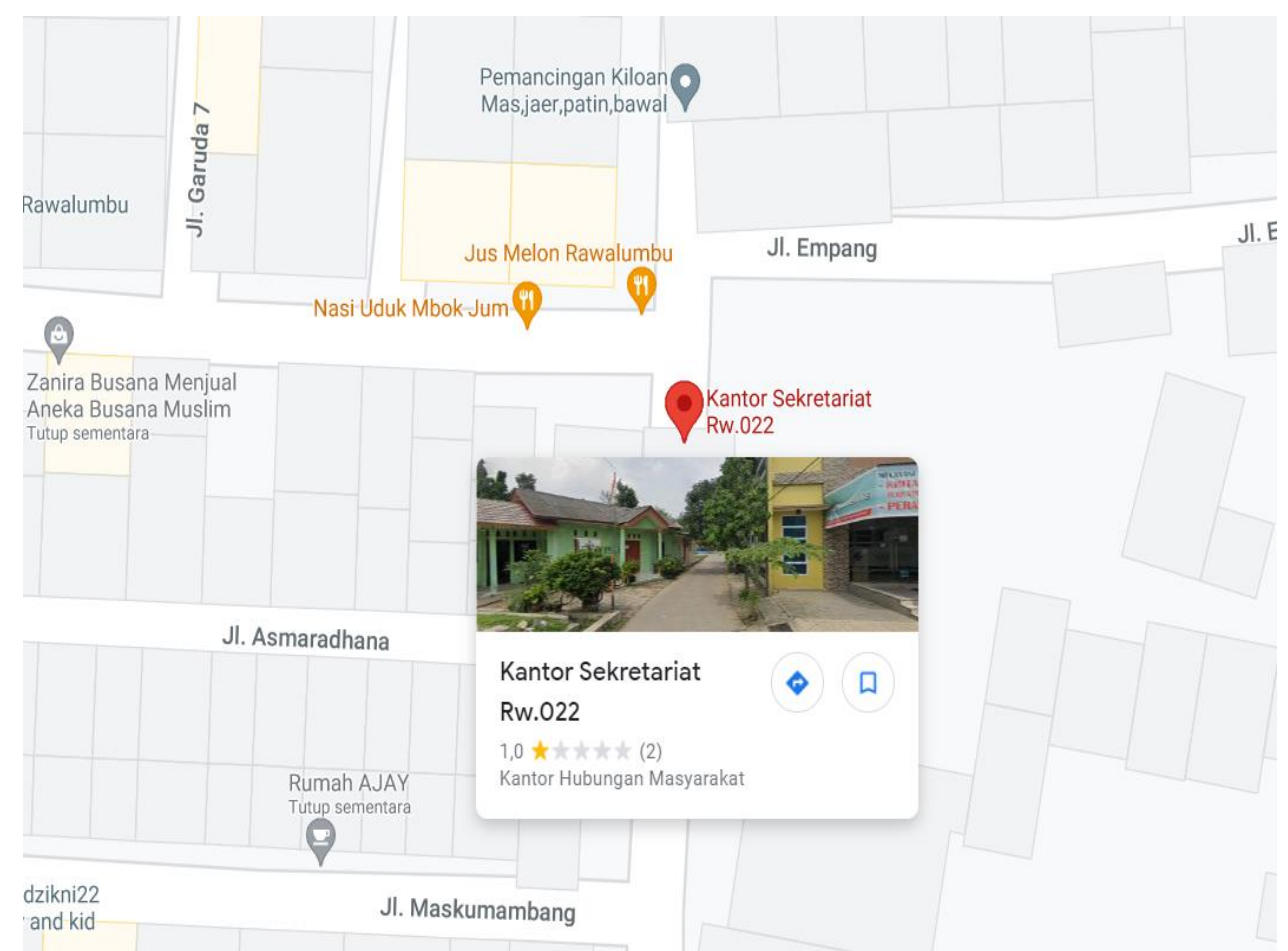

Sumber: Hasil Pelaksanaan (2021)

Gambar 2. Lokasi Karang taruna Katana 22

\subsection{Pelaksanaan}

Pengabdian kepada Masyarakat ini diadakan pada hari Sabtu tanggal 19 Juni 2021. Kegiatan pengabdian kepada masyarakat dimulai dari pukul 09.00 sampai dengan pukul 12.00 WIB melalui media zoom meeting. Media zoom meeting ini dipilih agar kegiatan pengabdian kepada masyarakat ini tidak melanggar protocol kesehatan di era pandemi Covid-19. Pelaksanaan kegiatan pengabdian kepada masyarakat ini dihadiri peserta berjumlah 10 peserta.

Link Zoom Meeting :

https://us04web.zoom.us/j/72434707556?pwd=ZGMyWU50WnRJYVJuVmFHU25RczBBZz09 Meeting ID : 72434707556

Passcode : hRF37Q 


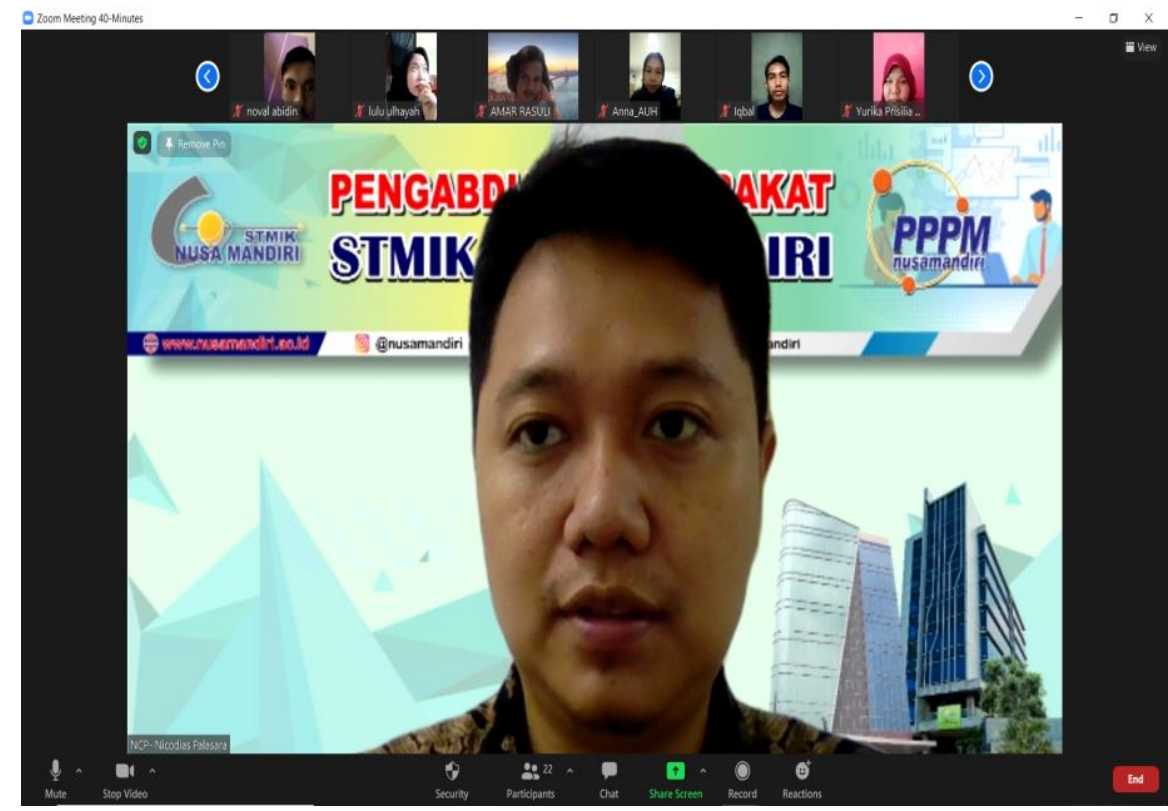

Sumber: Hasil Pelaksanaan (2021)

Gambar 3. Sambutan dari Ketua Pengabdian Masyarakat.

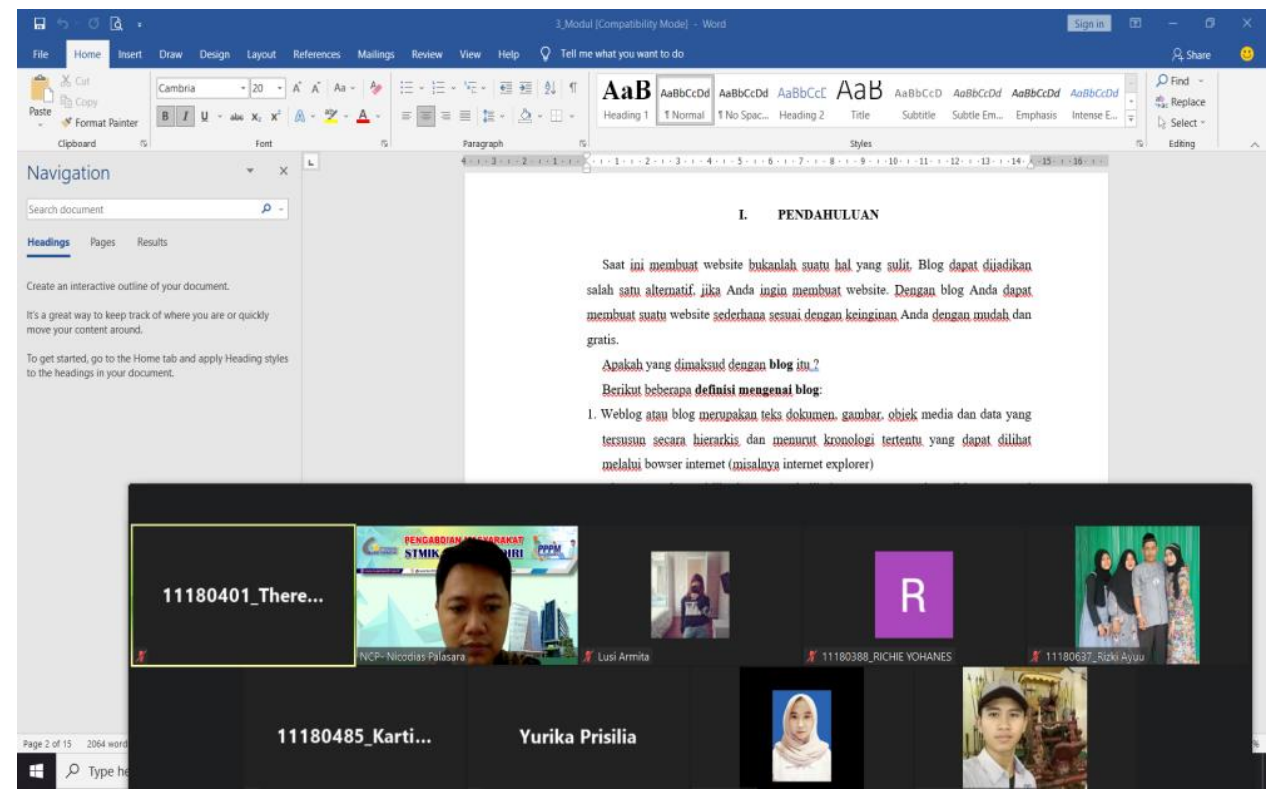

Sumber: Hasil Pelaksanaan (2021)

Gambar 4. Pemaparan materi mengenai pengenalan blog dari tim tutor

Pada gambar 3 terlihat ketua pengabdian masyarakat ini, yaitu bapak Nicodias Palasara, M.Kom memberikan sambutan. Pada gambar 4 terlihat tim tutor memaparkan materi mengenai blog kepada anggota Karang Taruna Katana 22. Tim tutor dari Universitas Nusa Mandiri terdiri dari Ibu Anna Mukhayaroh, Ibu Adelia Alvi Yana, Ibu Juarni Siregar, dan Ibu Ani Yoraeni dan dibantu juga oleh mahasiswa Universitas Nusa Mandiri. 


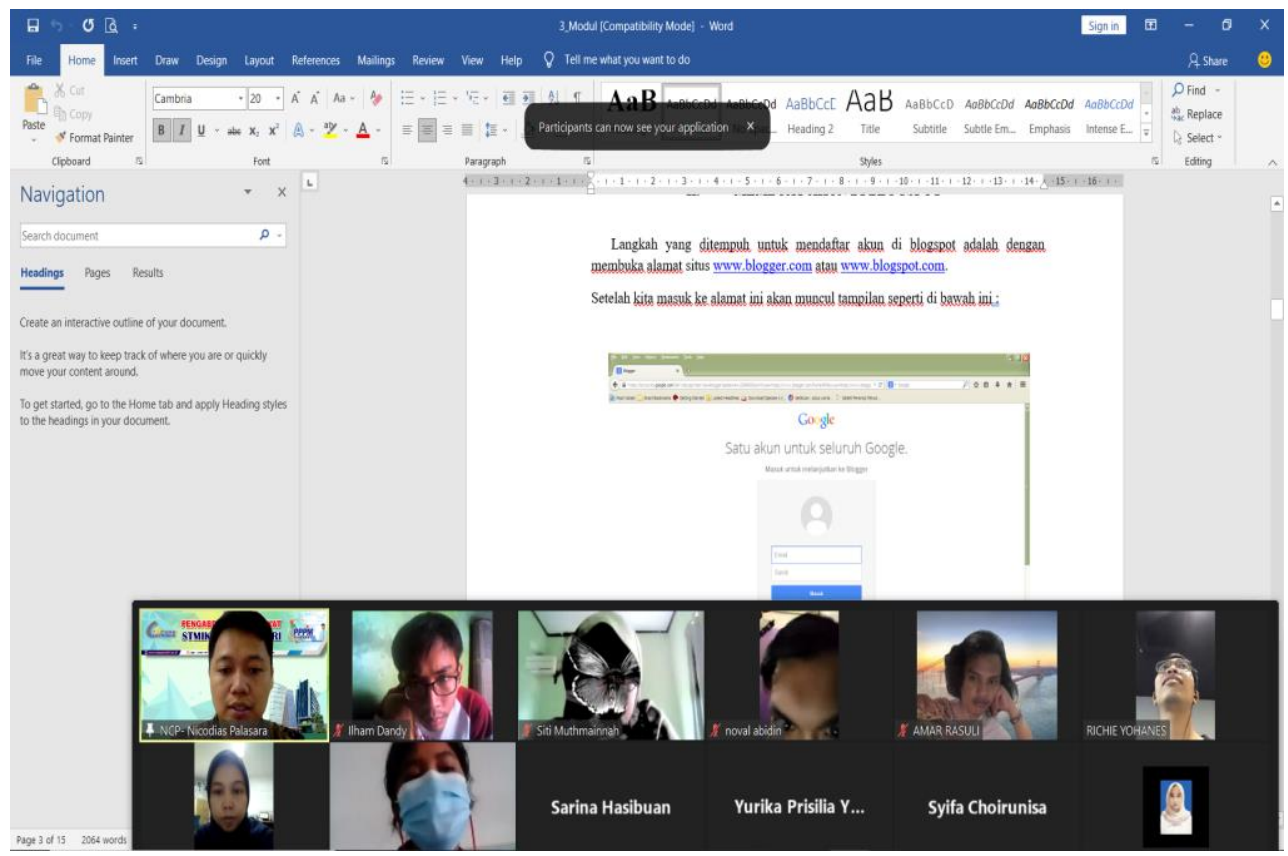

Sumber: Hasil Pelaksanaan (2021)

Gambar 5. Anggota Karang Taruna Katana 22 membuat blog sesuai instruksi tim tutor

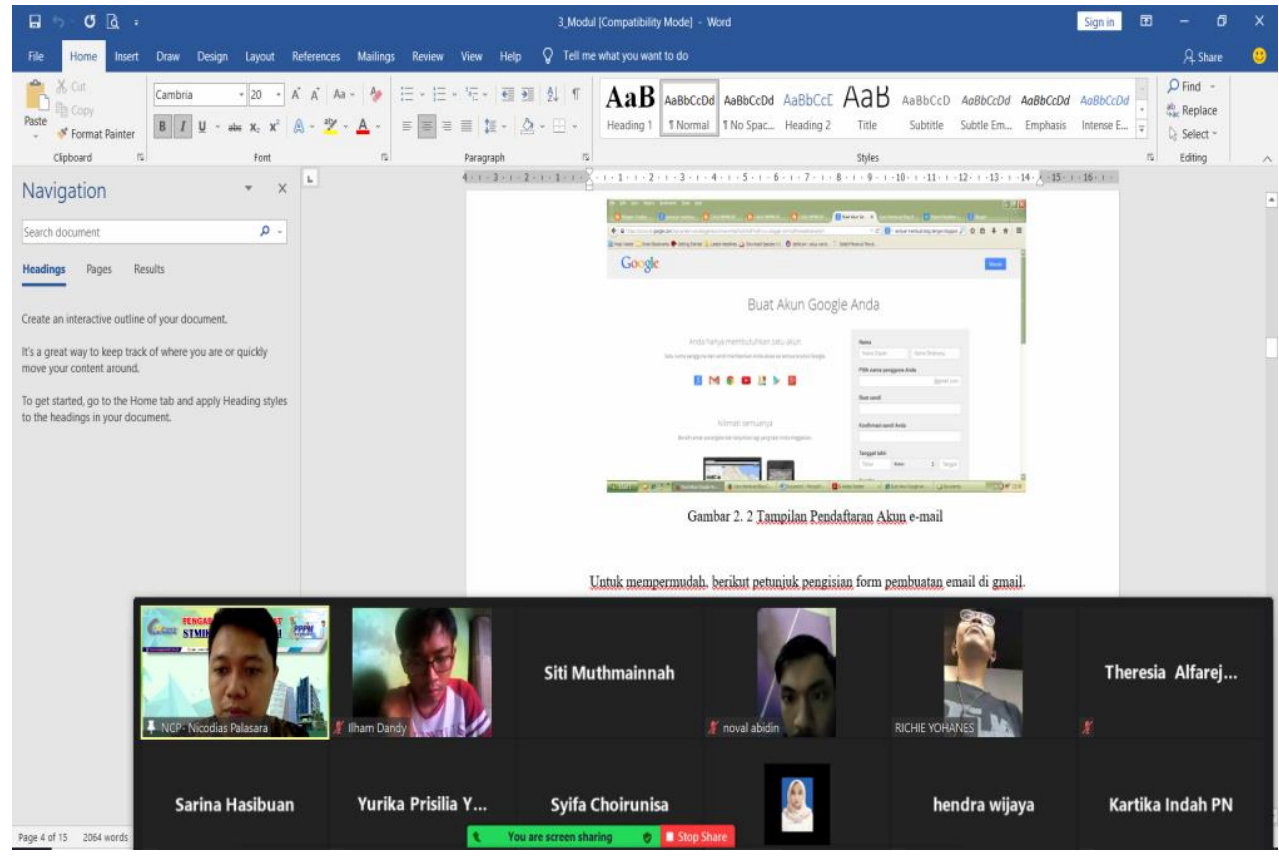

Sumber: Hasil Pelaksanaan (2021)

Gambar 6. Tim tutor menjelaskan cara membuat blog secara bertahap kepada peserta pelatihan 


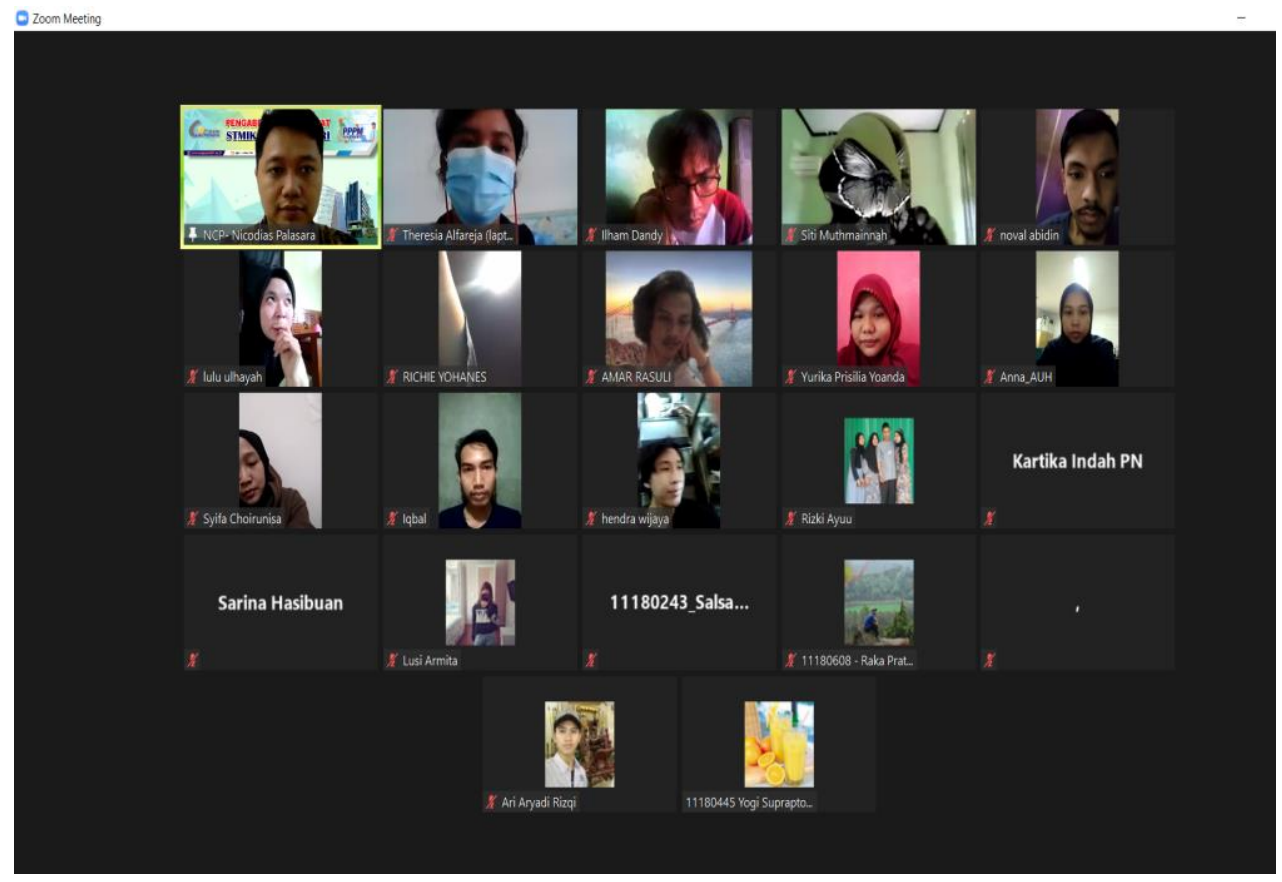

Sumber: Hasil Pelaksanaan (2021)

Gambar 7. Tim tutor menjawab pertanyaan dari para anggota Karang Taruna Katana 22

Peserta pengabdian masyarakat sangat antusias dengan pemberian materi oleh dosen Univeristas Nusa Mandiri Jakarta. Hal ini terlihat dengan banyaknya pertanyaan yang diajukan peserta kepada Tutor Pengabdian Masyarakat. Kegiatan ini terlaksana dengan baik dengan dukungan warga masyarakat serta remaja sampai dengan berakhirnya acara. Pelaksanaan kegiatan pengabdian kepada masyarakat ini berjalan dengan lancar, tertib tanpa ada kendala yang berarti dan tentunya dengan menerapkan protokol kesehatan di masa pandemi Covid-19 ini.

\section{Kesimpulan}

Berdasarkan hasil pelaksanaan kegiatan pengabdian kepada masyarakat di Karang Taruna Katana 22 dapat disimpulkan beberapa hal, yaitu para remaja sebenarnya berada di masa-masa ingin berbagi banyak hal dengan kawan-kawannya namun dikarenakan pandemi sehingga mereka tidak dapat berkumpul oleh karenanya dibutuhkan wadah untuk membuat tulisan dan menyampaikan kegiatan serta kurangnya pengetahuan dalam membuat blog. Maka dosen dan mahasiswa Universitas Nusa Mandiri mencoba memberikan solusi berupa pelatihan dalam membuat blog dari awal hingga terbangunnya blog yang dinamis dan mengajari bagaimana cara mempercantik blog sehingga pembaca menjadi antusias degan blog yang dibuat. Dampak dari solusi tersebut adalah kerja sama yang baik antar pemuda karang taruna dan RW untuk memberikan penyuluhan agar membangkitkan minat ketertarikan untuk untuk 
menulis dan Dengan dibangun sarana promosi digital melalui blog diharapkan, para generasi muda dapat menjadi generasi penerus karang taruna.

\section{Ucapan Terima Kasih}

Kami menyampaikan ucapan terima kasih kepada para remaja anggota Karang taruna Katana 22 dan Sekretariat RW 022, Perumahan Taman Narogong Indah, Kelurahan Pengasinan, Kecamatan Rawalumbu Kota Bekasi karena sudah bersedia menerima dan bersedia mengikuti kegiatan pengabdian kepada masyarakat dengan sangat baik. Begitu juga kepada seluruh pimpinan, dosen dan juga mahasiswa Universitas Nusa Mandiri karena telah memberikan dukunganbagi kami dalam melaksanakan salah satu dharma sebagai dosen, melalui kegiatan pengabdian kepada masyarakat.

\section{Daftar Pustaka}

Adi, M. R. Arief, A. S. (2014). Peran Karang Taruna Dalam Pembinaan Remaja Di Dusun Candi Desa Candinegoro Kecamatan Wonoayu Kabupaten Sidoarjo. Kajian Moral Dan Kewarganegaraan, 1(2), 190-205. Peran karang taruna dalam pembinaan remaja di dusun candi Desa Candinegoro Kecamatan Wonoayu Kabupaten Sidoarjo

Fajriah, N., Siroj, R. A., Matematika, P., \& PGRI Bandar Lampung, S. (2017). Ciptaan disebarluaskan di bawah Lisensi Creative Commons Atribusi-BerbagiSerupa 4.0 Internasional. Pengembangan Blog Untuk Mendukung Pembelajaran Pada Mata Kuliah Media Pembelajaran Matematika. Jurnal Edumath, 3(2), 89-100.

Fatmawati, A. (2015). Pengembangan Media Blog Sebagai Sarana Informasi Untuk Meningkatkan Kemampuan Perencanaan Karir Di Sman 1 Bulukumba. Jurnal Psikologi Pendidikan Dan Konseling: Jurnal Kajian Psikologi Pendidikan Dan Bimbingan Konseling, 1(2), 163. https://doi.org/10.26858/jpkk.v1i2.1814

Fitria. (2013). 済無No Title No Title. Journal of Chemical Information and Modeling, 53(9), 1689-1699.

Kemenkes RI. (2014). Permenkes Nomor 25 Tahun 2014.

Khairul Basyar, A. W. M. A. (2017). Pengembangan E-portofolio Tematik-Terpadu Berbasis Web Blog untuk Menanamkan Karakter Kritis dan Kreatif melalui Pembelajaran IPA. Phenomenon: Jurnal Pendidikan MIPA, 7(1), 30-39. https://doi.org/10.21580/phen.2017.7.1.1499

Pressmann, R. S. (2015). Softeware Engineering A Practitioner's Approach Seventh Edition.

Ratnasari, A., \& Hamdan, Y. (2015). Penggunaan Blog Sebagai Media Penunjang Kompetensi Dosen The Use Of Blog As Supporting Media For Competence Of Lecturer. Jurnal Penelitian Komunikasi, 18(1), 89-100.

Rhamandica, C., Wonorahardjo, S., \& Arief, M. (2016). Pengaruh Pembelajaran Berbasis Web Terhadap Hasil Belajar Mahasiswa Jurusan Kimia pada Materi Kimia Inti dengan Kemampuan Self Regulated Learning Berbeda. Jurnal Pendidikan - Teori, Penelitian, Dan 
Pengembangan, 1(10), 1891-1896. https://doi.org/10.17977/jp.v1i10.6895

Sunismi, S., \& Fathani, A. H. (2017). Prototipe Model Collaborative Learning Matematika Melalui Media Blog dengan Interactive Digital Book Mata Kuliah Kalkulus II. Jurnal Fourier, 6(2), 69. https://doi.org/10.14421/fourier.2017.62.69-83

Weni, D. M., \& Isnani, G. (2016). Meningkatkan Hasil Belajar Siswa dengan Pengembangan Media Pembelajaran E-Learning Berbasis Blog. Jurnal Pendidikan Bisnis Dan Manajemen, 2(2), 114-123. http://journal2.um.ac.id/index.php/jpbm/article/view/1697/969 